\title{
Mesalazine in inflammatory bowel disease: A trendy topic once again?
}

\author{
Marietta lacucci MD ${ }^{1}$, Shanika de Silva MRCP², Subrata Ghosh MD FRCPC FRCP FRCPE²
}

M Iacucci, S de Silva, S Ghosh. Mesalazine in inflammatory bowel disease: A trendy topic once again? Can J Gastroenterol 2010;24(2):127-133

5-aminosalicylic acid (5-ASA) preparations (eg, mesalazine, mesalamine) are well-established preparations used in the management of inflammatory bowel disease. These drugs are most useful for the treatment of mild to moderate flares of ulcerative colitis and, especially, for maintenance of remission. Although most gastroenterologists are very familiar with these drugs, the interest in these drugs has undergone a resurgence, with new preparations offering convenience and high dosage, while preserving their customary safety. New dosage regimens are likely to become standard practice in the near future. There is also considerable interest in chemoprevention of colorectal cancer in the context of inflammatory bowel disease, and the role of long-term maintenance therapy with 5-ASAs in achieving such chemoprevention. A mechanism of action for such chemoprevention has been provided by the agonism of the peroxisome proliferator-activated receptor-gamma by 5-ASA, which unifies its efficacy as an anti-inflammatory and chemopreventive agent. In the future, even more effective agents based on 5-ASA are expected, based on more powerful agonism of peroxisome proliferator-activated receptor-gamma; 5-ASA preparations have become 'trendy' again.

Key Words: 5-ASA; Adherence; Colorectal cancer; Delayed release; Inflammatory bowel disease; Mesalamine; Multimatrix system

U lcerative colitis (UC) and Crohn's disease (CD) are chronic relapsing conditions generally characterized by repetitive cycles of active and quiescent disease. Intestinal inflammation can result in bleeding and anemia, perforation with abscess or fistula formation, or subsequent fibrosis with intestinal obstruction (1). The natural history of inflammatory bowel disease (IBD) is dependent on the anatomical extent of involvement and activity of disease. The anatomical location and behaviour of CD, according to the Vienna (2) (or the more recent Montreal) classification, changes over time. At diagnosis, CD is located in the terminal ileum in $47 \%$, the colon in $28 \%$, the ileocolon in $21 \%$ and the upper gastrointestinal tract in $3 \%$ of patients. Disease behaviour is classified as nonstricturing and nonpenetrating in $70 \%$ of patients, stricturing in $17 \%$ and penetrating (fistulas or abscesses or both) in $13 \%$ of all patients at diagnosis. In clinical practice, disease activity is typically described as mild to moderate (ambulatory patients able to tolerate oral alimentation without manifestations of dehydration, toxicity, abdominal tenderness, painful mass, obstruction or more than $10 \%$ weight loss), moderate to severe disease (failure to respond to treatment for mild disease, more prominent symptoms of fever, weight loss, abdominal pain or tenderness, intermittent nausea, and vomiting without

\section{La mésalazine dans la maladie inflammatoire de l'intestin : De nouveau à la mode?}

Les préparations d'acide 5-aminosalicylique (5 ASA) (p. ex., mésalazine, mésalamine) sont couramment utilisées dans la prise en charge des maladies inflammatoires de l'intestin. Ces médicaments sont surtout utiles pour le traitement des poussées de légères à modérées de la colite ulcéreuse et notamment pour le maintien de la rémission. Bien que la plupart des gastro-entérologues connaissent bien ces agents, l'intérêt à leur endroit renaît actuellement, puisque de nouvelles préparations offrent la même commodité en doses plus fortes, tout en préservant le profil d'innocuité habituel. Les nouveaux schémas posologiques risquent de devenir la norme dans un avenir rapproché. On s'intéresse également beaucoup à la chimioprévention du cancer colorectal dans le contexte de la maladie inflammatoire de l'intestin et au rôle du traitement d'entretien prolongé par 5-ASA pour parvenir à cette chimioprévention. On a proposé comme mode d'action de cette chimioprévention l'agonisme des récepteurs gamma activé par les proliférateurs du peroxysome au moyen du 5-ASA, qui allie efficacité anti-inflammatoire et propriétés chimioprotectrices. On s'attend à ce que des agents à base de 5-ASA plus efficaces fassent leur apparition, en raison d'un effet agoniste plus puissant du récepteur gamma activé par les proliférateurs du peroxysome. Les préparations de 5-ASA sont revenues à la mode.

obstruction or significant anemia) and severe to fulminant disease (persisting symptoms on corticosteroids, high fevers, persistent vomiting or evidence of intestinal obstruction) (2-4). In UC, $55 \%$ of patients have proctitis, approximately $30 \%$ of patients present with left-sided or distal colitis and only approximately $15 \%$ of patients present with extensive colitis. However, subsequent proximal extension occurs in approximately $35 \%$ of patients with initial proctitis or left-sided colitis. Similar to CD, the severity of UC is classified as mild, moderate, severe or fulminant. It is estimated that approximately $71 \%$ of patients present with moderately active UC, whereas $20 \%$ present with mildly active disease (5). Initial therapy for patients with mild to moderate IBD depends on the location and extent of disease, with oral or rectal therapies being used individually or in combination. Severe or fulminant disease requires hospitalization and intensive parenteral therapy.

The goals of drug treatment in IBD are the induction and maintainance of remission, achieving mucosal healing, the avoidance of surgical intervention and decreasing the likelihood of cancer developing as a result of chronic inflammation.

Mesalazine is useful in controlling active inflammation, maintaining remission and for chemoprevention. It has the advantage of being generally well-tolerated and safe for long-term use with

${ }^{1}$ Gastrointestinal Unit, Hammersmith Hospital, Imperial College Healthcare NHS Trust, London, United Kingdom; ${ }^{2}$ Division of Gastroenterology, University of Calgary, Calgary, Alberta

Correspondence: Dr Subrata Ghosh, Division of Gastroenterology, University of Calgary, Teaching Research and Wellness Centre,

6th Floor, 3280 Hospital Drive Northwest, Calgary, Alberta T2N 4N1. Telephone 403-592-5010, fax 403-592-5080, e-mail ghosh@ucalgary.ca Received for publication March 20, 2009. Accepted March 21, 2009 
TABLE 1

Different dose and delivery system of 5-aminosalicylic acid (ASA) formulations

\begin{tabular}{|c|c|c|c|c|}
\hline $\begin{array}{l}\text { Generic 5-ASA } \\
\text { name }\end{array}$ & Commercial name & $\begin{array}{l}\text { Dose per tablet, } \\
\text { capsule or sachet, mg }\end{array}$ & Formulation & Site(s) of delivery \\
\hline Mesalazine & Pentasa* & $500,1000,2000$ & $\begin{array}{l}\text { Ethylcellulose-coated microgranules (slow, continuous } \\
\text { release) }\end{array}$ & Duodenum to rectum \\
\hline Mesalamine & Mezavant/Lialda ${ }^{\ddagger}$ & 1200 & Eudragit S-coated multimatrix system & Terminal ileum, colon \\
\hline Mesalazine & Salofalk ${ }^{\S}$ & 250 & Eudragit L-coated tablets & Mid to distal ileum, colon \\
\hline Mesalazine & |pocol $\left.\right|^{\pi}$ & 400 & Enteric coated with Eudragit S & Terminal ileum, colon \\
\hline Olsalazine & Dipentum $\neq \ddagger$ & 250 & 5-ASA dimer linked by azo bond & Colon \\
\hline
\end{tabular}

${ }^{*}$ Shire Inc, USA; ${ }^{\dagger}$ Procter \& Gamble Pharmaceuticals, USA; ${ }^{\ddagger}$ Shire Inc, USA ${ }^{\S}$ Axcan Pharma Inc; ${ }^{\top}$ Sandoz Ltd, United Kingdom; **Pharmacia Ltd, United Kingdom;

${ }^{+\dagger}$ Salix Pharmaceuticals, USA; ${ }^{\sharp \neq}$ Celltech Pharmaceuticals Inc, USA

flexible dosing. Mesalazine, also known as mesalamine or 5-aminosalicylic acid (5-ASA), is the first-line treatment for IBD and remains the mainstay of treatment for mild to moderate $\mathrm{UC}$; however, its use in $\mathrm{CD}$ is controversial (6). Indeed, the European Crohn's and Colitis Organization Consensus recently stated that oral aminosalicylates are not recommended for the treatmetn of mild to moderate CD (7). However, both the American and British National Gastroenterology Associations recommend the use of high-dose 5-ASA for the first-line treatment of mild ileal, ileocolonic or colonic CD $(1,8)$. Clearly, there is conflicting evidence regarding the efficacy of oral aminosalicylates in active CD and their use in mild to moderate $\mathrm{CD}$ has been debated.

The action of mesalazine is believed to be predominantly topical at the site of inflammation, especially within the colon. The clinical aim, therefore, is to maximize delivery of the active drug - 5-ASA - to the colonic mucosa, while minimizing systemic absorption.

\section{DIFFERENT 5-ASA FORMULATIONS AND MECHANISMS OF ACTION}

5-ASAs are available in several oral and rectal (topical) formulations including tablets, micropellets (granules), suppositories and enemas, the latter may be aerosols, liquids or gels (Table 1).

Sulfasalazine was the first 5-ASA to be used for the treatment of symptoms and maintenance of remission in UC. It is composed of 5-ASA linked to sulfapyridine via a diazo bond that is cleaved by bacterial azoreductases in the colon to release the two components (9). Its use as a maintenance agent in UC is well documented, and in a meta-analysis of 11 trials involving 1598 patients (10), sulfasalazine had a slight therapeutic advantage over 5-ASA (OR 1.29; 95\% CI 1.05 to 1.57). Compared with olsalazine for the maintenance of remission, sulfasalazine was found to be significantly more effective when the ORs from five trials were pooled (OR 1.4; 95\% CI 1.07 to 1.84) (10). A meta-analysis investigating the failure to induce remission in active UC involving eight trials and 687 patients (6) demonstrated no significant differences between 5-ASA and sulfasalizine at induction of remission (OR 0.83; 95\% CI 0.6 to 1.13 ).

It is recognized that a subgroup of patients with IBD suffer from enteropathic arthropathy - a condition that can be divided into a pauciarticular, large joint arthropathy or a bilateral symmetrical polyarthropathy with or without axial involvement (11). Sulfasalazine has been shown to be beneficial in treating the synovitis associated with gut inflammation in UC rather than $\mathrm{CD}$, if used in early disease (less than five years) and in the presence of peripheral involvement (12). The efficacy of sulfasalazine in the treatment of spondyloarthropathy has been demonstrated in a multicentre, placebo-controlled trial involving more than 350 patients (13), showing greater efficacy over placebo with respect to laboratory markers of inflammation and patients' own assessment of disease. It was suggested in some treatment guidelines (1) that selected patients with UC and reactive arthropathy would benefit from treatment with sulfasalazine. Therefore, sulfasalazine continues to retain a place in management.

The use of sulfasalazine, however, is mainly limited by side effects associated with allergic reactions and high rates of intolerance (up to $20 \%$ ) to the sulfapyridine component. As a result, formulations based on the active moiety (ie, 5-ASA) have been evaluated and two main methods of 5-ASA delivery have been used. The first class is azobonded compounds that are controlled-release and $\mathrm{pH}$ dependent ( $\mathrm{pH} 6$ to 7). These molecules are nonabsorbable prodrugs that are cleaved in the colon by the bacterial enzyme azoreductase and released. Drugs that use this delivery strategy include balsalazide (Colazal, Salix Pharmaceuticals, USA) and olsalazine (Dipentum, Celltech Pharmaceuticals Inc, USA). The second class is a composite ( $\mathrm{pH}$-dependent combined with controlled release), in which the formulation contains a gastroresistant coating and a $\mathrm{pH} /$ transit-dependent controlled-release that prevents 5-ASA release until the drug reaches the distal ileum. Agents that use this strategy are delayed-release mesalazine tablets (Asacol, Procter \& Gamble Pharmaceuticals, USA), Salofalk tablets and Salofalk Granustix (Axcan Pharma Inc). Pentasa (Shire Inc, USA), in contrast to the formulations described above, releases 5-ASA from the duodenum to the rectum, and is often used 'off-label' to treat $\mathrm{CD}$ in addition to its indicated use for $\operatorname{UC}(14,15)$.

The mechanism of action of mesalazine as an antiinflammatory drug is diverse. It appears to act locally on colonic mucosa and reduces inflammation through a variety of anti-inflammatory processes. Several potential targets of 5-ASA action have been proposed. The current hypothesis is that 5-ASA activates a synthetic class of nuclear receptor. Peroxisome proliferator-activated receptor (PPAR)-gamma is a 
key receptor that mediates the effect of 5-ASA therapy in IBD by transrepressing several key target genes such as nuclear factor $\mathrm{B}$, signal transducers and activators of transcription. It has a role in the regulation of intestinal inflammation and is highly expressed in the colon, where epithelial cells and macrophages are the main cellular sources of this nuclear receptor. PPARgamma is also involved in cell proliferation, apoptosis, and modulation of cytokine production and antitumourigenic effects. Therefore, PPAR-gamma may form the basis for chemopreventive strategies against colorectal cancer (CRC).

However, additional mechanisms of action of mesalamine have been described. These include the inhibition of mediators of lipoxygenase and cyclooxygenase, interleukin-1, interleukin-2 and tumour necrosis factor-alpha. 5-ASA has also been recognized as a potent antioxidant and free-radical scavenger (16-22).

\section{CLINICAL IMPLICATIONS OF MEDICATION NONADHERENCE IN IBD PATIENTS}

The reasons for noncompliance with 5-ASA therapy are complex. Male sex, single marital status, full-time employment and three-times daily dosing have all been identified as independent predictors of noncompliance (23).

Oral formulations that deliver 5-ASA topically to the disease activity site require multiple daily dosing, which is inconvenient. This multiple daily dosing can interfere with patient quality of life and can have a negative impact on drug adherance (24).

Moreover, several studies have demonstrated that mucosal concentrations of azobonded or bolus-release 5-ASA formulations are highest in the right-sided colon, whereas in the leftsided colon, concentrations are much lower. A cross-sectional study of American outpatients with quiescent UC (25) found that only $40 \%$ were adherent to maintenance mesalazine therapy. Several community-based studies have reported nonadherence rates in IBD patients ranging from $43 \%$ to $72 \%$. Nonadherence to medication has important clinical implications in UC and CD patients, including increased risk of relapses, possible risk of developing $\mathrm{CRC}$ and the health care costs of managing poor disease control (25-28).

\section{Increased risk of relapse}

In a cohort study of 99 patients with quiescent UC (29), whose adherence to 5-ASA medication was monitored for two years, 39 patients experienced a recurrence of their symptoms, of whom 32 (82\%) were nonadherent to their prescribed medication. Patients who did not adhere to their medication had a greater than fivefold risk of disease recurrence than adherent patients (hazard ratio 5.5; 95\% CI 2.3 to 13 ; $\mathrm{P}<0.001$ ). The reasons for nonadherence to their prescribed regimen were the following: 21 patients $(30 \%)$ said there were too many pills, $14(20 \%)$ believed they did not need so much medication and $35(50 \%)$ reported that they 'just forgot'. The investigators also found that patients with quiescent UC who failed to adhere to their prescribed 5-ASA regimen had a $61 \%$ chance of relapse compared with only $11 \%$ among patients who adhered to their prescribed therapy - a difference that was statistically significant $(\mathrm{P}=0.001)$. It is possible, but unlikely, that patients who relapse more often do not take their medication because they believe it is ineffective (30).

\section{Increased risk of developing $\mathrm{CRC}$}

Patients with IBD affecting the colon are at an increased risk of developing CRC. The risk of developing CRC increases with the extent and duration of UC and is associated with a lifetime risk of approximately 20\% (31). In addition, data from population-based studies indicate that $\mathrm{CD}$ patients have an increased risk of CRC similar to that of UC patients. Prevention strategies such as surveillance, drug treatment, and regular doctor visits are warranted and probably effective. In a 10-year cohort study of 175 patients with UC, Moody et al (32) demonstrated that the incidence of CRC was significantly higher $(\mathrm{P}<0.001)$ in patients $(31 \%)$ who did not adhere to or discontinued sulfasalazine therapy, compared with only a $3 \%$ incidence in those who continued with long-term treatment.

These results were confirmed in a case-control analysis conducted by Van Staa et al (33) using a study population of 18,969 patients. Regular users, defined as having six or more 5-ASA prescriptions in the previous 12 months, were found to have a lower risk of CRC than irregular users (crude OR 0.7, 95\% CI 0.44 to 1.03 ; adjusted OR $0.60,95 \%$ CI 0.38 to 0.96 ). These results show some reduction in the risk of CRC developing in UC patients who adhere to regular 5-ASA use. Furthermore, conclusions from a systematic review and meta-analysis of nine observational studies involving almost 2000 patients (34) also supported the protective role of 5-ASA against CRC development. More rigorous randomized controlled trials are unlikely, and the effect size of this protection may be debated and can be variable. Chronic inflammation may be the trigger for the colitis-dysplasia-carcinoma sequence; 5-ASA may mitigate this process by decreasing inflammation, and may act in a more direct way by promoting apoptosis in neoplastic cells by decreasing epithelial cell turnover.

\section{Increased health care costs}

Strategies to improve adherence are important to reduce the high direct and indirect costs of a relapse. The high percentage of nonadherent patients who have a relapse was associated with a two- to threefold increase in the costs for nonhospitalized cases, with a 20-fold increase in costs for hospitalized cases compared with quiescent cases of IBD (35). Over a six-month period, the total direct cost of caring for patients with IBD ranged from UK $£ 73$ (approximately US \$129) to UK £33,254 (US $\$ 58,980)$. The mean cost of care over six months for patients with UC was UK $£ 1,256$ (US \$2,228) and, while only $67(14 \%)$ patients with IBD required hospitalization during the six-month assessment period, they accounted for $49 \%$ of the total secondary care costs.

\section{STRATEGIES TO OPTIMIZE DOSE AND ADHERENCE OF 5-ASA IN IBD: 'NEW' 5-ASA FORMULATIONS}

The ideal therapy would be an oral formulation, with fewer tablets, requiring less frequent dosing and no side effects. More recently, the introduction of promising new mesalamine formulations (Table 2), offering high-dose and less frequent or once-daily dosing regimens is likely to enhance patient compliance. These include mesalamine $800 \mathrm{mg}$ tablets (Asacol, Procter \& Gamble Pharmaceuticals, USA), 1.2 g multimatrix (MMX) system mesalamine tablets (Lialda, Shire Inc, USA), and $2 \mathrm{~g}$ (Pentasa) and $3 \mathrm{~g}$ 5-ASA granule sachets (Salofalk). 
TABLE 2

New developments in 5-aminosalicylic acid delivery mechanisms

\begin{tabular}{|c|c|c|}
\hline Formulation & Clinical trial & Author (reference) \\
\hline \multirow[t]{2}{*}{ Mesalamine (800 mg tablets) } & Asacol*, ASCEND I, II and III & Hanauer et al $(37,38)$ \\
\hline & & Sandborn et al (39) \\
\hline \multirow[t]{3}{*}{ Mesalazine micropellets (pH dependent) } & Pentasa $^{\dagger}$ (once daily) & Dignass and Veerman (45) \\
\hline & & Farup et al (46) \\
\hline & Salofalk ${ }^{\ddagger}$ (once daily) & Kruis et al (48) \\
\hline \multirow[t]{2}{*}{ Multimatrix (combined hydrophylic/lipophylic matrices) } & Multimatrix mesalamine & Kamm et al $(40,43)$ \\
\hline & & Lichtenstein et al (41) \\
\hline
\end{tabular}

*Procter \& Gamble Pharmaceuticals, USA; ' Shire Inc, USA; ${ }^{\ddagger}$ Axcan Pharma Inc. ASCEND Assessing the Safety and Clinical Efficacy of a New Dose of 5-ASA (37-39)

\section{Asacol (800 mg tablet)}

Earlier clinical trials comparing the efficacy of $1.6 \mathrm{~g} /$ day versus $4.8 \mathrm{~g} /$ day mesalamine (Asacol) in patients with mild to moderately active UC showed no definite differences in efficacy between the doses, although systematic reviews have shown a small benefit for higher doses in induction (36).

Recently, the Assessing the Safety and Clinical Efficacy of a New Dose of 5-ASA (ASCEND) I and II trials $(37,38)$ used a new $800 \mathrm{mg}$ tablet formulation of Asacol, comparing $4.8 \mathrm{~g} /$ day of delayed-release mesalamine with $2.4 \mathrm{~g} /$ day. In the first trial (ASCEND I) (37), 301 patients with mild to moderately active UC were randomly assigned to receive oral mesalamine $2.4 \mathrm{~g} /$ day (400 mg tablets) or $4.8 \mathrm{~g} /$ day ( $800 \mathrm{mg}$ tablets). The primary endpoint was the proportion of patients who achieved complete remission or a clinical response to therapy. Overall improvement occurred in $51.3 \%$ of patients (77 of 150$)$ treated with Asacol $2.4 \mathrm{~g} /$ day and $55.9 \%$ of patients (76 of 136) treated with $4.8 \mathrm{~g} /$ day $(\mathrm{P}=0.4411)$.

In the second trial (ASCEND II) (38), the design was amended to restrict the entry criteria to only 268 patients with moderately active UC. Seventy-two per cent of patients receiving mesalamine $4.8 \mathrm{~g} /$ day achieved treatment success at week 6 , compared with $59 \%$ of those who received $2.4 \mathrm{~g} /$ day $(\mathrm{P}=0.036)$. The results of this study suggest that an acceptable strategy may be that patients with mildly active UC be treated initially with Asacol $2.4 \mathrm{~g} /$ day and patients with moderately active UC with $4.8 \mathrm{~g} /$ day using the $800 \mathrm{mg}$ tablets - such a high dose in moderately active UC may also provide modestly faster symptom relief (38).

The recent ASCEND III (39) study confirmed the clinical benefit of delayed-release mesalamine $4.8 \mathrm{~g} /$ day in patients with moderately active UC. The overall improvement at week 6 was higher with the $4.8 \mathrm{~g}$ /day dose only in subgroups of patients who had received previous treatment with oral mesalamine, rectal therapies, steroids or multiple medications. The ASCEND program confirmed that high doses of 5-ASA were well tolerated and safe.

\section{MMX mesalamine ( $1.2 \mathrm{~g}$ tablet)}

MMX mesalamine (MMX Lialda, USA; Mezavant XL, United Kingdom and Ireland, Mezavant, rest of Europe, Shire Pharmaceuticals Inc); offers a novel, high-strength (1.2 g/tablet) delivery system, and has been used in patients with active, mild to moderate UC. This delivery system uses lipophilic and hydrophilic matrices enclosed in a gastroresistant, $\mathrm{pH}$-dependent coating to facilitate prolonged exposure of the colonic mucosa to the active moiety. The delivery system has been likened to an absorbant sponge gradually breaking up and releasing 5-ASA throughout the colon.

The results of two large studies reported by Kamm et al (40) and Lichtenstein et al (41) have shown that MMX mesalamine $2.4 \mathrm{~g} /$ day (given once daily or as $1.2 \mathrm{~g}$ twice daily) or $4.8 \mathrm{~g} /$ day once-daily is well tolerated and efficacious for the induction of clinical and endoscopic remission in patients with active, mild to moderate UC. The UC disease activity index score in these studies was modified by assigning the friability parameter a score of 2 . Approximately $64 \%$ of patients in these studies did not achieve strictly defined remission by endoscopic and clinical parameters by eight weeks of treatment with MMX mesalamine. Those not achieving remission after eight weeks were treated with steroids or other immunosuppressive therapies (42).

In a long-term, open-label, phase III study, Kamm et al (43) evaluated the effect of prolonged, high-dose, oral 5-ASA treatment over 12 months. The remission rate was similar to that observed in the parent study ( $57 \%$ to $61.5 \%$ ). The eight-week extension part of the study suggests that some patients who appear refractory to 5-ASA may require only an extended treatment with the high-dose MMX mesalamine ( $4.8 \mathrm{~g} /$ day) as an alternative to step-up steroid therapy.

The current licensed dose of MMX mesalamine for the induction of remission in patients with active, mild to moderate $\mathrm{UC}$ is two to four $1.2 \mathrm{~g}$ tablets administered once daily. The recommended dose for the maintenance of remission is $2.4 \mathrm{~g}$ once daily (44).

\section{Once-daily 5-ASA granules}

Pentasa or Salofalk granules are micropellet formulations of 5-ASA preferred by some patients, especially those reluctant to swallow relatively large tablets.

In a recent multicentre, investigator-blinded, randomized controlled trial, patients with mild to moderate UC in remission were randomly assigned to a $2 \mathrm{~g}$ sachet of mesalazine granules (Pentasa) once daily or a $1 \mathrm{~g}$ sachet of mesalazine granules twice daily. At one year, $74 \%$ and $64 \%$ of patients in the oncedaily and twice-daily groups, respectively, maintained clinical and endoscopic remission. Once-daily dosing was clinically superior to, and had a higher adherence than twice daily dosing (45). Farup et al (46) compared the efficacy of an equal dose of a prolonged-release granule formulation of mesalazine (4 g/day, Pentasa sachet) divided into twice daily versus four times daily, with that of prolonged-release mesalazine tablets at two doses of $0.5 \mathrm{~g}$ four times daily in 227 patients with mild to moderately active UC. Granules were as effective as tablets, and twice- 
daily dosing was as effective as more frequent dosing (46). Once again, the study was designed to confirm the noninferiority of the granule formulation to the tablet formulation. In another study, the pharmacokinetic profile of 5-ASA for Pentasa sachets administered $4 \mathrm{~g}$ once daily was also similar to that of $2 \mathrm{~g}$ given twice daily. Patient compliance was 97\% (47).

Salofalk is a multiparticulate, granular formulation of mesalazine, with an enteric, acid-resistant film coating that enables prolonged release in the colon. This formulation is easier to swallow than enteric-coated tablets and may be preferred by some patients.

In a recent multicentre phase III trial, Kruis et al (48) demonstrated that once-daily dosing with mesalazine $3 \mathrm{~g}$ (Salofalk granules, Falk Pharma, Germany) was as effective as threetimes daily dosing with mesalazine $1 \mathrm{~g}$ for the treatment of active UC. A total of 380 patients were evaluated for efficacy and safety by intention-to-treat analysis, with $79.1 \%$ in the once-daily dosing group and $75.7 \%$ in the three-times daily group achieving remission $(\mathrm{P}<0.0001$ for noninferiority). Of interest is the significantly greater therapeutic effect of the once-daily dosing in proctosigmoiditis patients. This supports the hypothesis that once-daily dosing leads to higher luminal peak concentrations in the distal colon and that mesalazine granules are well suited for oral treatment of distal disease. In fact, most patients with UC tend to prefer the oral over the rectal route of administration (48).

\section{Rectal-oral 5-ASA combination therapy}

Rectally administered 5-ASA has also been shown to be superior to placebo for the maintenance of remission of distal UC (49-52). A meta-analysis (53) has demonstrated the superiority of rectal 5-ASA over placebo for maintenance of remission in UC at one year (OR 15.2; 95\% CI 4.7 to 55.9) .

Rectal 5-ASA is superior to rectal steroid therapy. In addition to patients with left-sided UC of mild to moderate severity, combined therapy also enhances the benefit in patients with extensive, mild to moderately active UC. In a randomized double-blind study performed in 127 ambulatory patients with extensive mild/moderate active UC (54), all subjects received oral mesalazine $4 \mathrm{~g}$ /day (twice daily dosing) for eight weeks. During the initial four weeks, they received an additional enema at bedtime containing $1 \mathrm{~g}$ of mesalazine or placebo. Remission was achieved in $44 \%$ of the mesalazine enema group versus $34 \%$ of the placebo enema group at four weeks $(\mathrm{P}=0.31)$, and in $64 \%(95 \%$ CI $50 \%$ to $76 \%)$ of the mesalazine enema group versus $43 \%$ of the placebo enema group at eight weeks $(\mathrm{P}=0.03)$ (54).

Similar studies with other preparations of 5-ASA, especially the new formulations, are required to demonstrate whether combination oral-rectal therapy offers benefit. Whether such combination therapy offers advantage over simply increasing the dose of oral preparation also requires further study.

\section{Rectal 5-ASA therapy}

Foam and gel preparations are generally better tolerated than liquid enemas. Adherence requires motivation and some training, as well as choice of the most appropriate delivery device. Increased dosing regimens do not generally enhance the benefit of rectal delivery and once-daily is sufficient. Inflammation at the distal rectum may require the use of a 5-ASA suppository.

\section{TABLE 3}

Treatment approach in ulcerative colitis using 5-aminosalicylic acid (5-ASA)

Induction of remission
Mild extensive: Oral 5-ASA + rectal 5-ASA
Mild distal: Rectal 5-ASA
Moderate extensive: High dose 5-ASA + rectal 5-ASA for 2 weeks; if
unresponsive, start steroids
Moderate distal: Rectal 5-ASA + oral 5-ASA, or rectal 5-ASA + rectal steroids
Maintenance of remission
Once-daily regimen for convenience in all patients
Distal disease: Maintenance rectal 5-ASA

\section{CONCLUSIONS}

Mesalazine, mesalamine or 5-ASA are the first-line therapy for patients with mild to moderate UC and remain the mainstay of maintenance therapy. Current delivery formulations, such as oral and rectal 5-ASA, present many limitations including inconvenience, poor-adherence dosing (number of tablets) and dose frequency (three to four times daily dosing), lack of efficacy in all types of UC and CD, and poor patient acceptability. Therefore, twice-daily dosing is common and once-daily dosing is now a reality. The use of 5-ASA preparations in the management of UC is summarized in Table 3.

Nonadherence to a prescribed regimen of 5-ASA has been shown to dramatically increase the risk of relapse, resulting in decreased quality of life and increased health care and personal costs. Adherence to 5-ASA therapy has also been associated with a possibly reduced risk of CRC. Indeed, the benefit of 5-ASA in the primary prevention of dysplasia and CRC in UC has been established and generally accepted despite the lack of double-blind, randomized studies.

New formulations of mesalazine have been developed and show promise in improving compliance and efficacy. These new 5-ASA formulations, with less frequent or once-daily administration, and with different delivery systems include micropellet and MMX oral formulations, as well as rectal gel and once-daily suppository formulations, have demonstrated efficacy in active mild to moderately active UC and in the maintenance of remission. Although more robust evidence is necessary, it is likely that 5-ASA preparations will be widely used for chemoprevention of CRC in UC and, as such, probably should also be used in colonic CD. Several studies have also demonstrated that these novel formulations are safe, offer a simplified dose regimen, and result in improved quality life and possibly compliance in patients, with pharmacoeconomic benefits. In the future, new 5-ASA preparations with more effective PPAR-gamma modulation are anticipated. It is likely that higher doses of the new formulations will be tested again for efficacy in CD as well.

\section{REFERENCES}

1. Carter MJ, Lobo AJ, Travis SP. Guidelines for the management of inflammatory bowel disease in adults. Gut 2004;53:1-16.

2. C Gasche, J Scholmerich, J Brynskov, et al. A simple classification of Crohn's disease: Report of the Working Party for the World Congresses of Gastroenterology, Vienna 1998. Inflamm Bowel Dis 2000;6:8-15. 
3. MS Silverberg, J Satsangi, Ahmad T, et al. Toward an integrated clinical, molecular and serological classification of inflammatory bowel disease: Report of the Working Party of the 2005 Montreal World Congress of Gastroenterology. Can J Gastroenterol 2005;19(Suppl A):5-36.

4. Louis E, Collard A, Oger AF, Degroote E, Aboul Nasr El Yafi FA, Belaiche H. Behaviour of Crohn's disease according to the Vienna classification: Changing pattern over the course of the disease. Gut 2001;49:777-82.

5. E Langholz, P Munkholm, M Davidsen, Binder V. Course of ulcerative colitis: Analysis of changes in disease activity over years. Gastroenterology 1994;107:3-11.

6. Sutherland L, Macdonald JK. Oral 5-aminosalicylic acid for induction of remission in ulcerative colitis. Cochrane Database Syst Rev 2006;3:CD000543.

7. Travis SP, Stange EF, Lemann M, et al. European evidence-based consensus on the diagnosis and management of Crohn's disease: Current manangement. Gut 2006;55(Suppl 1):16-35.

8. Hanauer SB, Sandborn W. Management of Crohn's disease in adults. Am J Gastroenterol 2001;96:635-43.

9. Peppercorn MA, Goldman P. The role of intestinal bacteria in the metabolism of salicylazo-sulfapyridine. J Pharmacol Exp Ther 1972;181:555-62.

10. Sutherland L, Macdonald J. Oral 5-aminosalicylic acid for maintenance of remission in ulcerative colitis. Cochrane Database Syst Rev 2006;2:CD000544.

11. Orchard TR, Wordsworth BP, Jewell DP. Peripheral arthropathies in inflammatory bowel disease: Their articular distribution and natural history. Gut 1998;42:387-91.

12. Padovan M, Castellino G, Govoni M, Trotta F. The treatment of rheumatological manifestations of the inflammatory bowel diseases. Rheumatol Int 2006;26:953-8.

13. Dougados M, van der Linden S, Lerislao-Repo M, et al. Sulfasalazine in the treatment of spondylarthropathy. A randomised, multicenter, double-blind placebo-controlled study. Arthritis Rheum 1995;38:618-27.

14. Desreumaux P, Ghosh S. Review article: Mode of action and delivery of 5-aminosalicylic acid-new evidence. Aliment Pharmacol Ther 2006;24(Suppl 1):2-9.

15. McCormack PL, Robinson DM, Perry CM. Delayed-release multi-matrix system (MMX) mesalazine in ulcerative colitis. Drugs 2007:67:2635-42.

16. Rousseaux C, Lefebvre B, Dubuquoy L, et al. Intestinal antiinflammatory effect of 5 -aminosalicylic acid is dependent on peroxisome proliferator-activated receptor-gamma. J Exp Med 2005;201:1205-15.

17. Stenson WF, Lobos E. Sulfasalazine inhibits the synthesis of chemotactic lipids by neutrophils. J Clin Invest 1982;69:494-7.

18. Mahida YR, Lamming CE, Gallagher A, Hawthorne AB, Hawkey CJ. 5-Aminosalicylic acid is a potent inhibitor of interleukin-1 beta production in organ culture of colonic biopsy specimens from patients with inflammatory bowel disease. Gut 1991;32:50-4.

19. Rachmilewitz D, Karmeli F, Schwartz LW, Simon PL. Effect of aminophenols (5-ASA and 4-ASA) on colonic interleukin-1 generation. Gut 1992;33:929-32.

20. Kaiser GC, Yan F, Polk DB. Mesalamine blocks tumor necrosis factor growth inhibition and nuclear factor kappa B activation in mouse colonocytes. Gastroenterology 1999;116:602-9.

21. Egan LJ, Mays DC, Huntoon CJ, et al. Inhibition of interleukin-1. stimulated NF-kappa B RelA/p65 phosphorylation by mesalamine is accompanied by decreased transcriptional activity. J Biol Chem 1999;274:26448-53.

22. Ahnfelt-Ronne I, Nielsen OH, Christensen A, et al. Clinical evidence supporting the radical scavenger mechanism of 5-aminosalicylic acid. Gastroenterology 1990;98:1162-9.

23. Hawthorne AB, Rubin G, Ghosh S. Review article: Medication non-adherence in ulcerative colitis - strategies to improve adherence with mesalazine and other maintenance therapies. Aliment Pharmacol Ther 2008;27:1157-66.

24. Kane SV, Cohen RD, Aikens JE, Hanauer SB. Prevalence of nonadherence with maintenance mesalamine in quiescent ulcerative colitis. Am J Gastroenterol 2001;96:2929-33.

25. Rubin G, Hungin AP, Chinn D, et al. Long-term aminosalicylate therapy is under-used in patients with ulcerative colitis: A cross-sectional survey. Aliment Pharmacol Ther 2002;16:1889-93.
26. Bernal I, Domènech E, Garcia-Planella E, et al. Medication-taking behaviour in a cohort of patients with inflammatory bowel disease. Dig Dis Sci 2006;51:2165-9.

27. López-San Román A, Bermejo F, Carrera E, Pérez-Abad M, Boixeda D. Adherence to treatment in inflammatory bowel disease. Rev Esp Enferm Dig 2005;97:249-57.

28. Shale MJ, Riley SA. Studies of compliance with delayed-release mesalazine therapy in patients with inflammatory bowel disease. Aliment Pharmacol Ther 2003;18:191-8.

29. Kane S, Huo D, Aikens J, et al. Medication non-adherence and outcomes of patients with quiescent ulcerative colitis. Am J Med 2003;114:39-43

30. Hjortswang H, Jarnerot G, Curman B, et al.The influence of demographic and disease-related factors on health-related quality of life in patients with ulcerative colitis. Eur J Gastroenterol Hepatol 2003;15:1011-20.

31. Brentnall TA. Molecular underpinnings of cancer in ulcerative colitis. Curr Opin Gastroenterol 2003;19:64-8.

32. Moody GA, Jayanthi V, Probert CS, et al. Long-term therapy with sulphasalazine protects against colorectal cancer in ulcerative colitis: A retrospective study of colorectal cancer risk and compliance with treatment in Leicestershire. Eur J Gastroenterol Hepatol 1996;8:1179-83.

33. Van Staa TP, Card T, Logan RF, et al. Aminosalicylate use and colorectal cancer risk in inflammatory bowel disease: A large epidemiological study. Gut 2005;54:1573-8.

34. Velayos FS, Terdiman JP, Walsh JM. Effect of 5-aminosalicylate use on colorectal cancer and dysplasia risk: A systematic review and meta-analysis of observational studies. Am J Gastroenterol 2005;100:1345-53.

35. Bassi A, Dodd S, Williamson P, et al. Cost of illness of inflammatory bowel disease in the UK: A single centre retrospective study. Gut 2004;53:1471-8.

36. Kruis W, Bar-Meir S, Feher J, et al. The optimal dose of 5-aminosalicyclic acid active ulcerative colitis: A dose-finding study with newly developed mesalamine. Clin Gastroenterol Hepatol 2003;1:36-43.

37. Hanauer SB, Sandborn WJ, Dallaire C, et al. Delayed-release oral mesalamine $4.8 \mathrm{~g} /$ day ( $800 \mathrm{mg}$ tablets) compared to $2.4 \mathrm{~g} /$ day (400 mg tablets) for the treatment of mildly to moderately active ulcerative colitis: The ASCEND I trial. Can J Gastroenterol 2007;21:827-34

38. Hanauer SB, Sandborn WJ, Kornbluth A, et al. Delayed-release oral mesalamine at $4.8 \mathrm{~g} /$ day ( $800 \mathrm{mg}$ tablet) for the treatment of moderately active ulcerative colitis: The ASCEND II trial. Am J Gastroenterol 2005;100:2478-85.

39. Sandborn WJ, Regula J, Feagan B, et al. Efficacy and safety of delayed-release oral mesalamine at $4.8 \mathrm{~g} / \mathrm{D}$ ( $800 \mathrm{mg}$ tablet) in the treatment of moderately active ulcerative colitis: Results of the Ascend III study. Gastroenterology 2009 [Epub ahead of print].

40. Kamm MA, Lichtenstein GR, Sandborn WJ, et al. Randomised trial of once- or twice-daily MMX mesalazine for maintenance of remission in ulcerative colitis. Gut 2008;57:893-902.

41. Lichtenstein GR, Kamm MA, Poddu P, et al. Effect of once- or twice-daily MMX mesalamine (SPD476) for the induction of remission of mild to moderately active ulcerative colitis. Clin Gastroenterol Hepatol 2007;5:95-102.

42. Lichtenstein GR, Kamm MA, Karlstadt R, et al. MMX mesalamine is effective for the maintenance of ulcerative colitis remission in both left-sided and extensive disease. Am J Gastroenterol 2007;102:(Suppl):462.

43. Kamm MA, Lichtenstein GR, Sandborn WJ, et al. Effects of extended MMX mesalamine therapy for acute, mild-to-moderate ulcerative colitis. Inflamm Bowel Dis 2009;15:1-8.

44. Kale-Pradhan PB, Pradhan RS, Wilhelm SM. Multi-matrix system mesalamine: To use or not to use. Ann Pharmacother 2008;42:265-9.

45. Dignass A, Veerman H. Once- versus twice-daily mesalazine (Pentasa) granules for the maintenance of remission in ulcerative colitis: Results from a multinational randomized controlled trial. Gut 2008;57(Suppl 1):2.

46. Farup PG, Hinterleitner TA, Lukas M, et al. Mesalazine $4 \mathrm{~g}$ daily given as prolonged-release granules twice daily and four times daily is at least as effective as prolonged-release tablets four times daily in patients with ulcerative colitis. Inflamm Bowel Dis 2001;7:237-42. 
47. Gandia P, Idier I, Houin G. Is once-daily mesalazine equivalent to the currently used twice-daily regimen? A study performed in 30 healthy volunteers. J Clin Pharmacol 2007;47:334-42.

48. Kruis W, Kiudelis G, Racz I, et al. Once daily versus three times daily mesalazine granules in active ulcerative colitis: A double-blind, double-dummy, randomized, non-inferiority trial. Gut 2009;58:233-40.

49. Marteau P, Crand J, Foucault J, et al. Use of mesalazine slow release suppositories $1 \mathrm{~g}$ three times per week to maintain remission of ulcerative proctitis: A randomised double blind placebo controlled multicentre study. Gut 1998;42:195-9.

50. D'Albasio G, Paoluzi P, Campieri M, et al. Maintenance treatment of ulcerative proctitis with mesalazine suppositories: A double-blind placebo-controlled trial. The Italian IBD Study Group. Am J Gastroenterol 1998;93:799-803.
51. Hanauer S, Good IL, Goodman MW, et al. Long-term use of mesalamine (Rowasa) suppositories in remission maintenance of ulcerative proctitis. Am J Gastroenterol 2000;95:1749-54.

52. Yokoyama H, Takagi S, Kuriyama S, et al. Effect of weekend 5 -aminosalicylic acid (mesalazine) enema as maintenance therapy for ulcerative colitis: Results from a randomized controlled study. Inflamm Bowel Dis 2007;13:1115-20.

53. Marshall JK, Irvine EJ. Rectal aminosalicylate therapy for distal ulcerative colitis: A meta-analysis. Aliment Pharmacol Ther 1995;9:293-300.

54. Marteau P, Probert CS, Lindgren S, et al. Combined oral and enema treatment with Pentasa (mesalazine) is superior to oral therapy alone in patients with extensive mild/moderate active ulcerative colitis: A randomised, double blind, placebo controlled study. Gut 2005;54:960-5. 


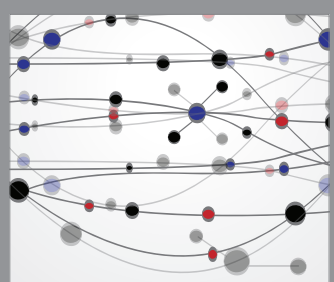

The Scientific World Journal
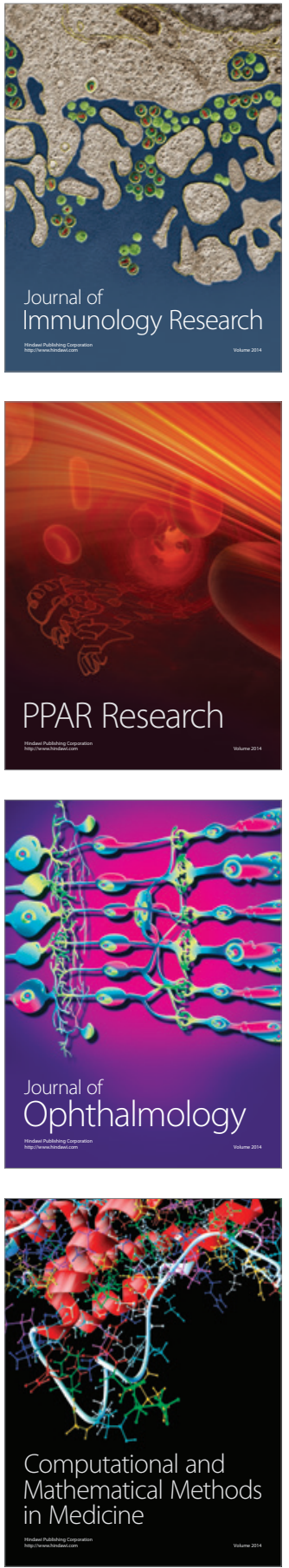

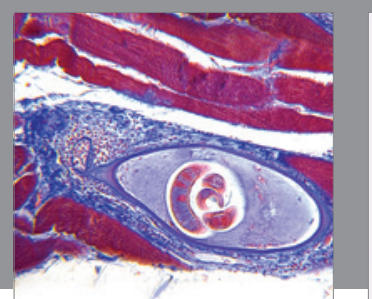

Gastroenterology Research and Practice

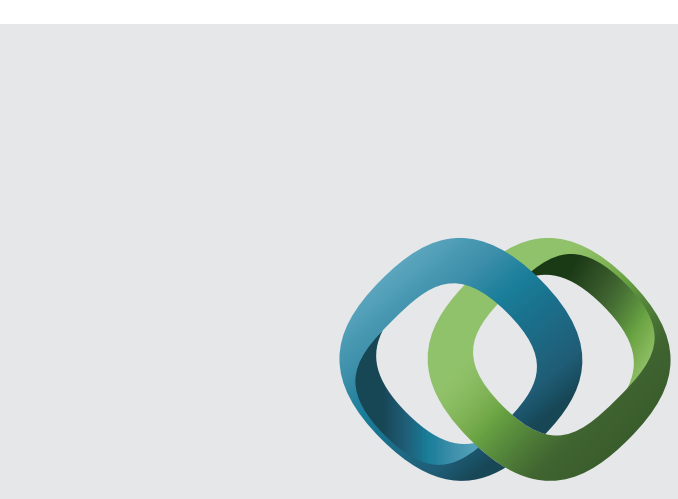

\section{Hindawi}

Submit your manuscripts at

http://www.hindawi.com
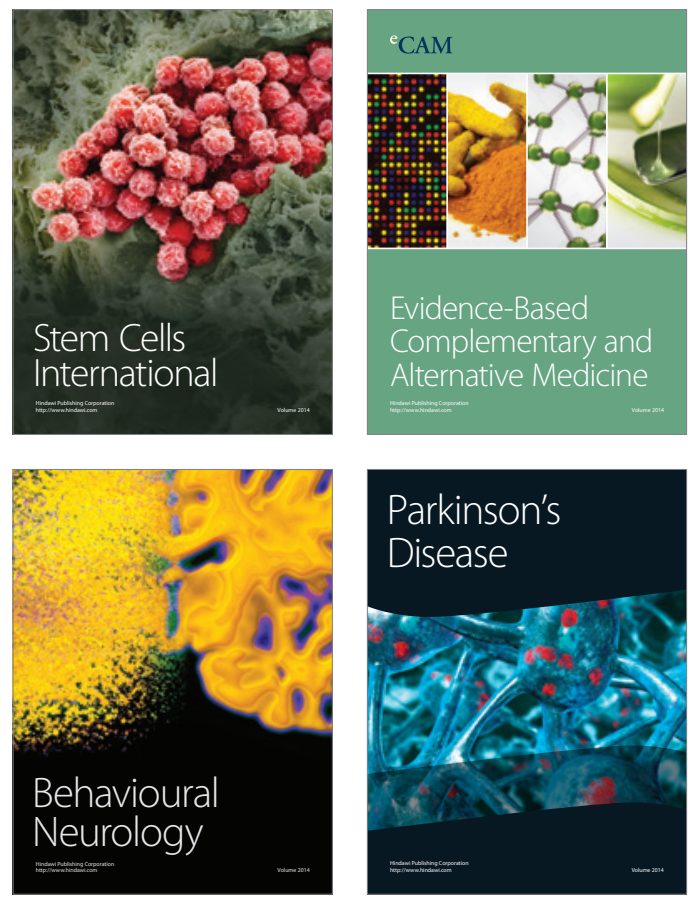
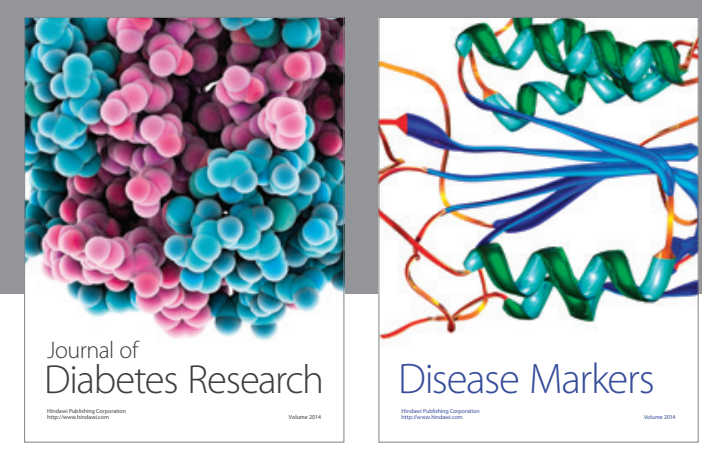

Disease Markers
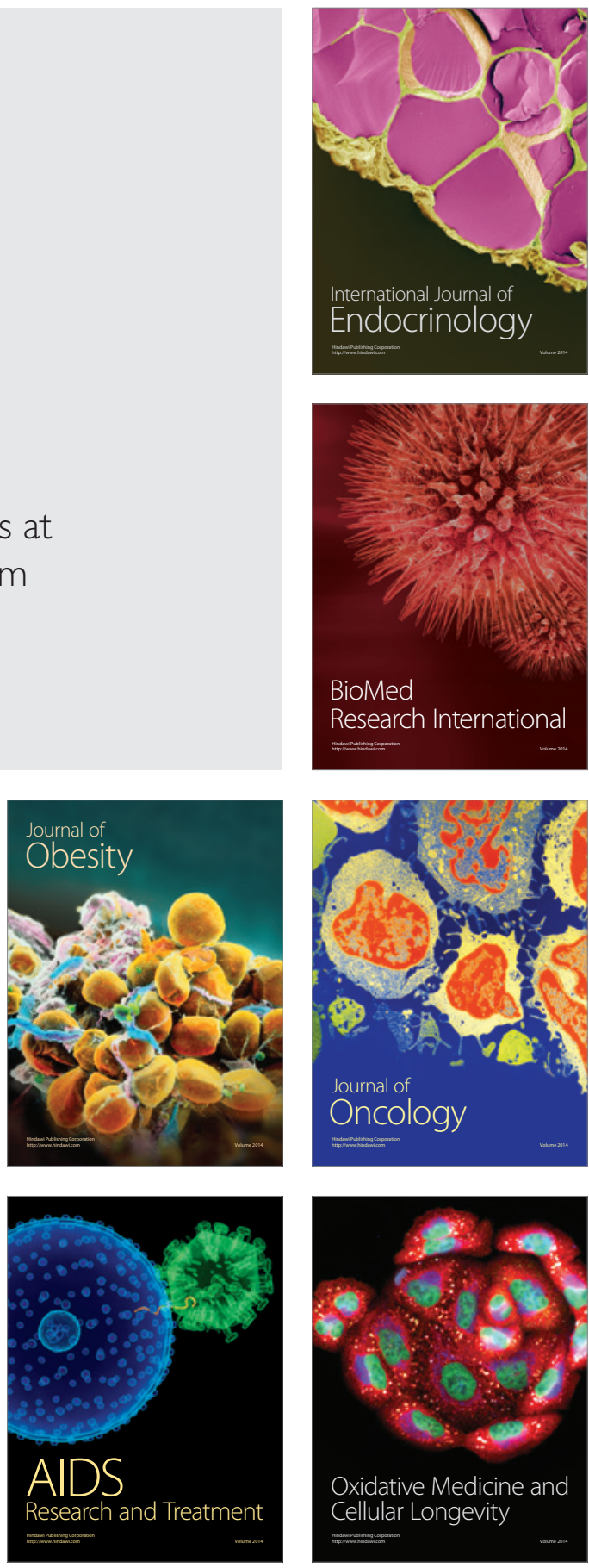